\title{
Antioxidant effect of quinoline derivatives containing or not selenium: Relationship with antinociceptive action quinolines are antioxidant and antinociceptive
}

\author{
ETHEL A. WILHELM ${ }^{1}$, ANA TERESINHA FERREIRA ${ }^{1}$, MIKAELA P. PINZ ${ }^{1}$, ANGÉLICA S. DOS \\ REIS $^{1}$, ANE G. VOGT ${ }^{1}$, ANDRE L. STEIN ${ }^{2}$, GILSON ZENI ${ }^{2}$ and CRISTIANE LUCHESE ${ }^{1}$ \\ ${ }^{1}$ Programa de Pós-Graduação em Bioquímica e Bioprospecção, Laboratório de Pesquisa em Farmacologia Bioquímica/ \\ LAFARBIO, Grupo de Pesquisa em Neurobiotecnologia/GPN, Centro de Ciências Químicas, Farmacêuticas e de \\ Alimentos, Universidade Federal de Pelotas, Campus Universitário, s/n, 96010-900 Capão do Leão, RS, Brazil \\ ${ }^{2}$ Programa de Pós-Graduação em Química, Departamento de Química, Centro de Ciências Naturais e Exatas, \\ Universidade Federal de Santa Maria, Av. Roraima, 1000, Camobi, 97105-900 Santa Maria, RS, Brazil
}

Manuscript received on October 5, 2016; accepted for publication on December 13, 2016

\begin{abstract}
The present study investigated the antioxidant effect of a new class of quinoline derivatives (a-d) on assays in vitro. Lipid peroxidation, thiol peroxidase-like and free radical scavenging activities were determined to evaluate antioxidant activity of compounds. Thiol oxidase-like and $\delta$-aminolevulinate dehydratase activities were performed as a toxicological parameter. A second objective of this study was to evaluate the in vivo antinociceptive effect of the compound with better antioxidant effect and without toxic effects in a model of nociception induced by formalin in mice. In liver, at $100 \mu \mathrm{M}$, compound a reduced the lipid peroxidation to the control levels, while compounds $\mathbf{c}$ and $\mathbf{d}$ partially reduced it. In brain, only compound d partially reduced the lipid peroxidation at 50 and $100 \mu \mathrm{M}$. Compound $\mathbf{b}$ did not have an effect on the lipid peroxidation. Thiol peroxidase-like and free radical scavenging activities are not involved in the antioxidant mechanisms of these compounds. Compounds did not present thiol oxidase-like activity and effect on the $\delta$-aminolevulinate dehydratase. In vivo experiments showed that compound a caused an inhibition of licking time in the first and second phases, and edema formation induced by formalin. In conclusion, quinoline derivative without selenium presented better in vitro antioxidant effect and in vivo antinociceptive activity.
\end{abstract}

Key words: antinociceptive, antiedematogenic, anti-inflammatory, antioxidant, quinoline.

\section{INTRODUCTION}

Oxidative stress is defined as an imbalance between pro-oxidants and antioxidant systems. In fact it is characterized by an increase in the reactive

Correspondence to: Cristiane Luchese

E-mail: cristiane_luchese@yahoo.com.br

* Contribution to the centenary of the Brazilian Academy of Sciences. species (RS) production and/or a decrease in the antioxidant defenses. RS are a normal product of cellular metabolism, and they are involved in important biological functions. However, excessive production of RS may generate oxidative stress, causing tissue damage. Furthermore, several diseases are related to oxidative stress, such as such as cardiovascular and neurodegenerative diseases, 
cancer, atherosclerosis, rheumatoid arthritis, hypertension, ischemia and diabetes mellitus (Souza et al. 2009, Rajendran et al. 2014).

In this sense it is important to use antioxidant molecules that decrease oxidative stress, reducing the incidence of various diseases (Gay et al. 2010, Maes et al. 2011, Gupta et al. 2014). It is therefore important to highlight organoselenium compounds, which exhibit different pharmacological properties, such as antioxidant action (Nogueira and Rocha 2010, Luchese et al. 2012, Sancineto et al. 2016). Parallel to organoselenium compounds are quinoline derivatives. Quinolines are synthetic or natural heterocyclic compounds with interesting biological activities (Kouznetsov et al. 2005, Manjunatha et al. 2013).

Although several research groups have studied the mechanisms involved in the pharmacology of organochalcogens (Seng and Tiekink 2012, Ibrahim et al. 2012), the study of a quinoline derivative containing selenium could be an alternative to search for new compounds with antioxidant properties for the treatment of diseases related to oxidative stress. In addition, oxidative stress has been proposed as a mechanism involved in the pathophysiology of inflammation and pain (Abdel-Wahab and Salama 2011, Kubera et al. 2011). Pain and inflammation are a major clinical problem, and several undesirable side effects caused by the use of analgesic and antiinflammatory agents occur (Sheeba and Asha 2009, Riedel et al. 2015). In view of this, the development of new drugs with antinociceptive effects for the control of several painful conditions would be very useful as a therapeutic source.

Our research group has described the synthesis and pharmacological properties of quinolines and their derivatives, demonstrating potential antioxidant (Saraiva et al. 2016, Savegnago et al. 2013) and antinociceptive effects (Wilhelm et al. 2014, Pinz et al. 2016). Following our longstanding interest in pharmacological and toxicological properties of quinoline and its derivatives, this study investigated the in vitro antioxidant and toxicological effects of quinoline derivative containing or not selenium. Considering the results obtained in vitro, a second objective of this study was to investigate the in vivo antinociceptive activity of compound with better antioxidant effect and without toxic effects in a model of nociception induced by formalin in mice.

\section{MATERIALS AND METHODS}

\section{CHEMICALS}

2,4-diphenylquinoline (Figure 1a), 2,4-diphenyl3-(phenylselanyl)quinoline (Figure 1b), 6-chloro2,4-diphenyl-3-(phenylselanyl)quinoline (Figure 1c), 6-nitro-2,4-diphenyl-3-(phenylselanyl) quinoline (Figure 1d) were designated a, b, c and $\mathbf{d}$, respectively. These compounds were prepared according to the method found in the literature (Stein et al. 2015) and used at different concentrations $(\mu \mathrm{M})$ and doses $(\mathrm{mg} / \mathrm{kg})$. Analysis of the ${ }^{1} \mathrm{H}$ nuclear magnetic resonance and ${ }^{13} \mathrm{C}$ nuclear magnetic resonance spectra showed that all compounds synthesized exhibited analytical and spectroscopic data in full agreement with their assigned structures. Compounds a-d were dissolved in dimethyl sulfoxide to in vitro (initial concentration of $50 \mathrm{mM}$ ) assays and in canola oil for in vivo (initial concentration of $36 \mathrm{mM}$ ) experiments. Formalin was dissolved in saline (sodium chloride $0.9 \%$ ).

\section{ANIMALS}

The experiments were conducted using male adult Swiss mice (25-35 g). The animals were kept in a separate animal room, in a $12 \mathrm{~h}$ light/dark cycle (with lights on at 6:00 a.m.), at a room temperature of $22 \pm 2^{\circ} \mathrm{C}$, with free access to food and water. The experiments were performed according to the guidelines of the Committee on Care and Use of Experimental Animal Resources, Federal University of Pelotas, Brazil (CEEA 1987 and 
a

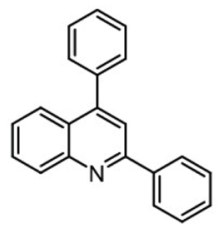

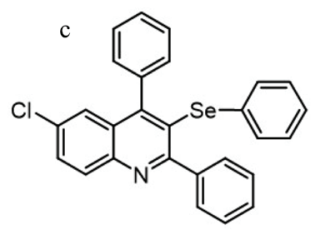

b
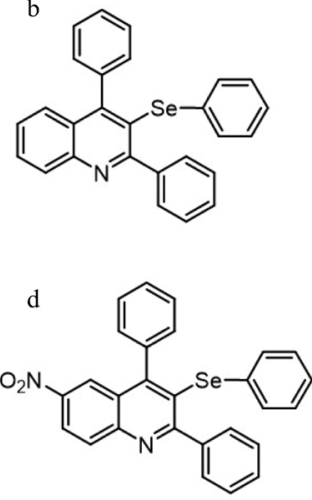

Figure 1 - Chemical structure of quinoline derivatives. (a) 2,4-diphenylquinoline; (b) 2,4-diphenyl-3-(phenylselanyl) quinoline; (c) 6-chloro-2,4-diphenyl-3-(phenylselanyl) quinoline; (d) 6-nitro-2,4-diphenyl-3-(phenylselanyl) quinoline.

1287-2016). The number of animals (104 animals) and intensities of noxious stimuli $(20 \mu \mathrm{l}$ of $2.5 \%$ formalin administered in the animals' paws used were the minimum necessary to demonstrate the consistent effects of the drug treatments. For in vivo experiments, 7 to 8 animals were used per group. For lipid peroxidation assays and $\delta$-aminolevulinate dehydratase ( $\delta$-ALA-D) activity, the experiments were performed 3 times and 1 animal was used for each experiment.

IN VITRO ASSAYS

\section{Tissue preparation}

Mice were euthanized by inhalation of isoflurane. Brain and liver tissues were rapidly dissected, weighed, placed on ice, homogenized in cold 50 mM Tris-HCl, pH 7.4 (1/5 for brains, 1/10 for livers, w/v) and centrifuged at $900 x \mathrm{~g}$ at $4^{\circ} \mathrm{C}$ for 10 minutes. Supernatant was used for lipid peroxidation analysis.
Thiobarbituric acid reactive species (TBARS) levels

TBARS production was performed as a measure of lipid peroxidation (Ohkawa et al. 1979). This assay was carried out to determine if compounds (a-d) protected against lipid peroxidation induced by sodium nitroprusside (SNP) in mouse brain and liver homogenates, indicating the antioxidant effect of compounds. An aliquot (200 $\mu$ f for brain, $100 \mu 1$ for liver) of supernatant was added to the reaction: SNP $(50 \mu \mathrm{M})$, compounds (a-d) $(1-100 \mu \mathrm{M})$ and $50 \mathrm{mM}$ Tris- $\mathrm{HCl}(30 \mu \mathrm{l})$. Afterward the mixture was pre-incubated for 1 hour at $37^{\circ} \mathrm{C}$. The reaction product was determined using $500 \mu 1$ thiobarbituric acid, $200 \mu 1$ sodium dodecyl sulphate (SDS), and $500 \mu \mathrm{l}$ acetic acid and incubated at $95^{\circ} \mathrm{C}$ for 2 hours. Absorbance was measured at $532 \mathrm{~nm}$ in a spectrophotometer. Results were reported as nmol malondialdehyde (MDA) /mg protein.

\section{2,2'-Diphenyl -1-picrylhydrazyl (DPPH) radicals scavenging activity}

The scavenging effect of DPPH radicals was performed to determine the possible mechanism by which the compounds (a-d) exhibit antioxidant property. In the DPPH assay, the reduction of DPPH radical by antioxidants could be for the donation of hydrogen atom to a free radical to remove the extra electron (which is responsible for the activity of free radicals) (Thaiponga et al. 2006). A DPPH stable radical assay was performed in accordance with Choi et al. (2002). Briefly, DPPH was added to a medium containing compounds (a-d) at different concentrations (1-100 $\mu \mathrm{M})$. The medium was incubated for 30 minutes at room temperature. The decrease in absorbance was measured at 517 $\mathrm{nm}$, which depicted the scavenging activity of compounds (a-d) against DPPH. Ascorbic acid (50 $\mu \mathrm{M}$ ) was used as a positive control. The values were expressed in percentage of blank: DPPH radicals 
scavenging activity $=($ absorbance of sample $\mathrm{x} 100)$ / absorbance of blank.

\section{2,2'-Azino bis-3-ethylbenzothiazoline-6 sulfonic acid (ABTS) radicals scavenging activity}

The scavenging effect of ABTS radicals was performed to determine the possible mechanism by which compounds (a-d) exhibit antioxidant property. ABTS is a protonated radical and it is used for evaluating the scavenger activity of proton radicals (Thaiponga et al. 2006). The ABST radical assay was performed in accordance with Re et al. (1999). In short, ABTS was added to a medium containing compounds (a-d) at different concentrations (1-100 $\mu \mathrm{M})$. The medium was incubated for 30 minutes at room temperature. The decrease in absorbance was measured at 734 $\mathrm{nm}$, which depicted the scavenging activity of compounds (a-d) against ABTS. Ascorbic acid (50 $\mu \mathrm{M}$ ) was used as a positive control. The values were expressed in percentage of blank: ABTS radicals scavenging activity $=($ absorbance of sample $\mathrm{x} 100)$ / absorbance of blank.

\section{Thiol peroxidase-like activity}

The antioxidant action of quinoline derivatives could be explained by their ability to mimic the activity of the thiol peroxidase enzyme. Indeed, several organoselenium compounds have a catalytic activity similar to that of the thiol peroxidase enzyme, reducing peroxides at the expense of thiol compounds (Mugesh and Singh, 2000, Nogueira et al. 2004).

Thiol peroxidase-like activity was carried out to determine the possible mechanism by which compounds (a-d) $(1-100 \mu \mathrm{M})$ have antioxidant properties. Free-SH groups were determined according to Ellman (1959). Compounds (a-d) were incubated in the medium containing reduced glutathione $(\mathrm{GSH})(1.0 \mathrm{mM})$ with and without $\mathrm{H}_{2} \mathrm{O}_{2}(0.3 \mathrm{mM})$ and checked after $120 \mathrm{~min}$, for the amount of GSH. The values are expressed in percentage of control.

\section{Thiol oxidase-like activity}

Thiol oxidase activity determines the prooxidant property of compounds. Thiol oxidation was determined with $50 \mathrm{mM}$ Tris- $\mathrm{HCl}, \mathrm{pH} 7.5$, compounds (a-d) $(1-100 \mu \mathrm{M})$ and addition of 1.0 $\mathrm{mM} \mathrm{GSH}$. Aliquots were checked for the amount of thiols groups. Free thiols groups were determined according to Ellman (1959). The values are expressed in percentage of control.

\section{$\delta-A L A-D$ activity}

$\delta$-ALA-D activity has been reported as sensitive to pro-oxidant compounds and heavy metals. $\delta$-ALA-D activity was used as a toxicity marker. $\delta$-ALA-D activity was assayed by the method of Sassa (1982) with some modifications. The principle of this method is based on the enzyme incubation with excess of $\delta$-aminolevulinic acid ( $\delta$-ALA). An aliquot $(200 \mu \mathrm{l})$ of supernatant was pre-incubated for 10 minutes at $37^{\circ} \mathrm{C}$ in the presence or absence of compounds (a-d) at different concentrations (1-100 $\mu \mathrm{M})$. Enzymatic reaction was initiated by adding the substrate ( $\delta$-ALA, $12 \mathrm{mM}$ ). The incubation was carried out for 3 hours at $37^{\circ} \mathrm{C}$. The reaction was stopped by adding trichloroacetic acid solution (10 $\%$ TCA) with $10 \mathrm{mM} \mathrm{HgCl}$. The porphobilinogen, which is formed during the incubation period, was mixed with modified Ehrlich's reagent, and the color developed was measured spectrophotometrically (555 nm) against a blank. Results were expressed as nmol porphobilinogen $(\mathrm{PBG}) / \mathrm{h} / \mathrm{mg}$ protein.

\section{Protein quantification}

Protein concentration was measured by the method of Bradford (1976), using bovine serum albumin as a standard. 


\section{IN VIVO EXPERIMENTS}

\section{Formalin-induced nociception}

The formalin test was carried out as described by Hunskaar and Hole (1987). Mice were pretreated with compound a $(1,10,50 \mathrm{mg} / \mathrm{kg}$, per oral route (p.o.)), meloxicam (50 mg/kg, p.o.) or an appropriate vehicle. After 30 minutes, the animals received the intraplantar (i.pl.) administration of formalin $(2.5 \%, \mathrm{v} / \mathrm{v} ; 20 \mu \mathrm{l} / \mathrm{paw})$ in the right hind paw and saline solution $(0.9 \%, \mathrm{w} / \mathrm{v} ; 20 \mu \mathrm{l} / \mathrm{paw})$ in the left paw. The animals were individually placed in an acrylic box and duration of paw licking was recorded at 0-5 $\mathrm{min}$ (first phase) and 15-30 min (second phase). The first phase is regarded as a neurogenic mechanism and the second phase as an inflammatory mechanism. After the period of observation, mice were sacrificed and the edema was measured. Paws were removed and weighed. The paw edema was measured by comparing the difference between the weight of the formalininjected paw and the weight of the contralateral paw (saline-treated paw).

\section{STATISTICAL ANALYSIS}

Data were expressed as mean \pm S.E.M. Statistical analysis was performed using a one-way ANOVA followed by the Newman-Keuls test when appropriate. Values of $\mathrm{p}<0.05$ were considered statistically significant. Maximal inhibition $\left(\mathrm{I}_{\max }\right.$ - maximum percentage by which an inhibitor reduced a response) was calculated at the most effective concentration used.

\section{RESULTS}

\section{EFFECT OF COMPOUNDS A-D ON TBARS LEVELS}

In the brain, compound $\mathbf{d}$ partially reduced the lipid peroxidation induced by SNP at concentrations equal to or greater than $50 \mu \mathrm{M}$, while compounds $\mathbf{a}, \mathbf{b}$ and $\mathbf{c}$ did not have any effect on the lipid
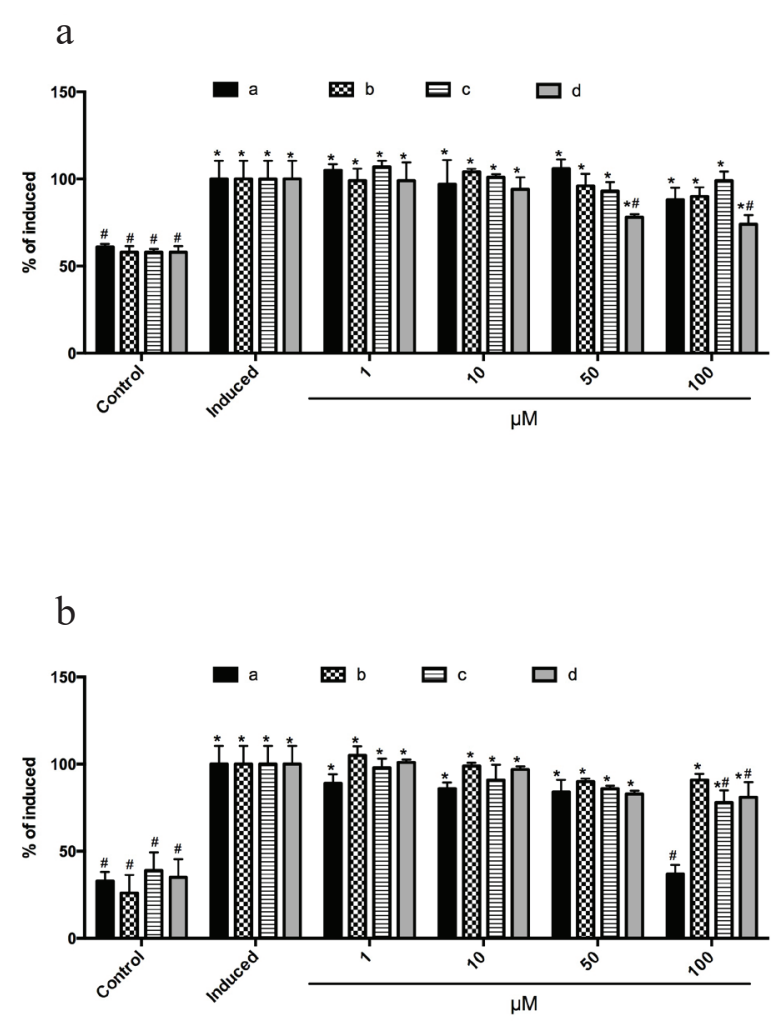

Figure 2 - Effect of compounds a - $\mathbf{d}$ on lipid peroxidation induced by SNP in the brain (a) and liver (b) of mice. Data are reported as mean \pm S.E.M. Statistical analysis was performed by One-way ANOVA followed by Newman-Keuls' test. (*) denotes $\mathrm{P}<0.05$ when compared to the control group. (\#) denotes $\mathrm{P}<0.05$ when compared to the induced group.

peroxidation (Figure 2a). $I_{\max }$ was in the following order: $\mathbf{d}(26 \%)>\mathbf{a}(12 \%)>\mathbf{b}(10 \%)>\mathbf{c}(1 \%)$.

In the liver, compound a was effective in reducing TBARS levels at a concentration equal to $100 \mu \mathrm{M}$ (Figure $2 \mathrm{~b}$ ). Compounds $\mathbf{c}$ and $\mathbf{d}$, at a concentration equal to $100 \mu \mathrm{M}$, partially reduced the lipid peroxidation induced by SNP, while compound $\mathbf{b}$ did not have any effect (Figure $2 b$ ). $I_{\max }$ was in the following order: a $(63 \%)>\mathbf{c}(22 \%)$ $>\mathbf{d}(19 \%)>$ b $(9 \%)$.

\section{EFFECT OF COMPOUNDS A-D ON DPPH RADICAL SCAVENGING ACTIVITY}

Compounds a-d, at all concentrations tested, did not present DPPH radical scavenging activity (data not shown). Ascorbic acid, a positive control, at 
the concentration of $50 \mu \mathrm{M}$ showed DPPH radical scavenging activity (data not shown).

EFFECT OF COMPOUNDS A-D ON ABTS RADICAL SCAVENGING ACTIVITY

Compounds a-d, at all concentrations tested, did not present ABTS radical scavenging activity (data not shown). Ascorbic acid, a positive control, at the concentration of $50 \mu \mathrm{M}$ showed ABTS radical scavenging activity (data not shown).

\section{EFFECT OF COMPOUNDS A-D ON THIOL} PEROXIDASE-LIKE ACTIVITY

Compounds a-d did not present thiol peroxidaselike activity (data not shown).

\section{EFFECT OF COMPOUNDS A-D ON THIOL OXIDASE-} LIKE ACTIVITY

Compounds a-d did not present thiol oxidase-like activity (data not shown).

\section{EFFECT OF COMPOUNDS A-D ON $\triangle$-ALA-D ACTIVITY}

Compounds a-d, at all concentrations tested, did not have an effect on $\delta$-ALA-D activity in the brain and liver of mice (data not shown).

\section{FORMALIN-INDUCED NOCICEPTION}

Compound a showed antinociceptive activity in the first (ANOVA: $\mathrm{F}_{4,33}=3.651, \mathrm{p}<0.05$ ) and the second (ANOVA: $\mathrm{F}_{4,33}=8.685, \mathrm{p}<0.0001$ ) phases of the formalin test, when compared to the control group (Figure $3 \mathrm{a}$ and $3 \mathrm{~b}$, respectively).

In the first phase, the animals pretreated with compound a, at the doses of 1,10 and $50 \mathrm{mg} / \mathrm{kg}$, reduced the licking time by 50, 67 and $57 \%(\mathrm{p}<$ $0.05)$, respectively (Figure 3a). Meloxicam (50 mg/ $\mathrm{kg}$ ), a reference drug, reduced the licking time (53 $\%)$ induced by formalin in the first phase $(p<0.05)$ (Figure 3a).

In the second phase, compound $\mathbf{a}$, at the doses of 1,10 and $50 \mathrm{mg} / \mathrm{kg}$, reduced the licking time

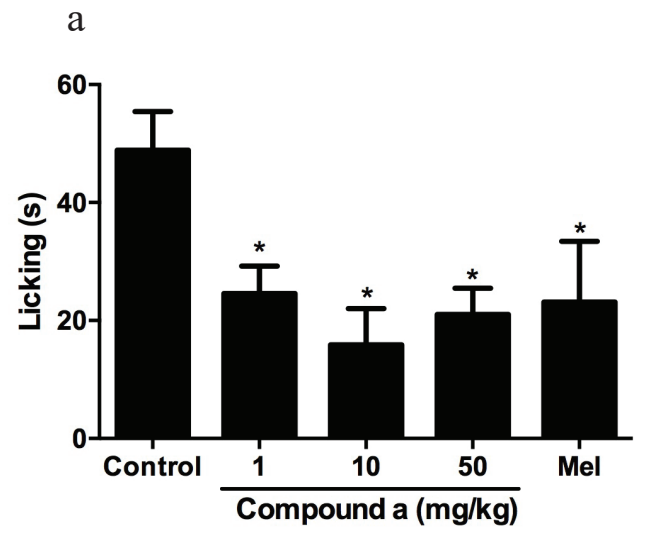

b

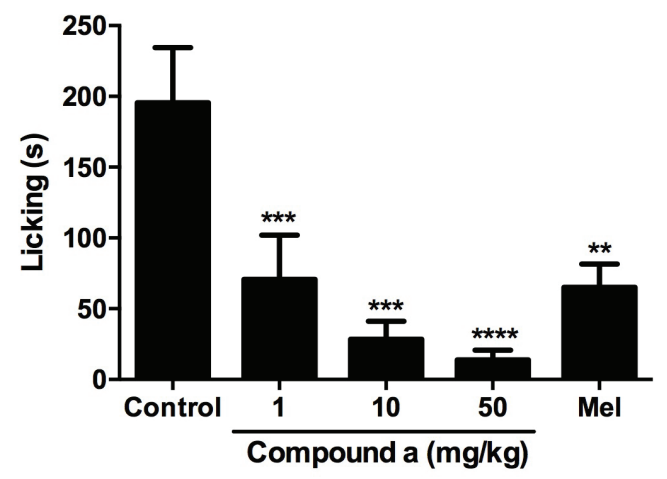

c

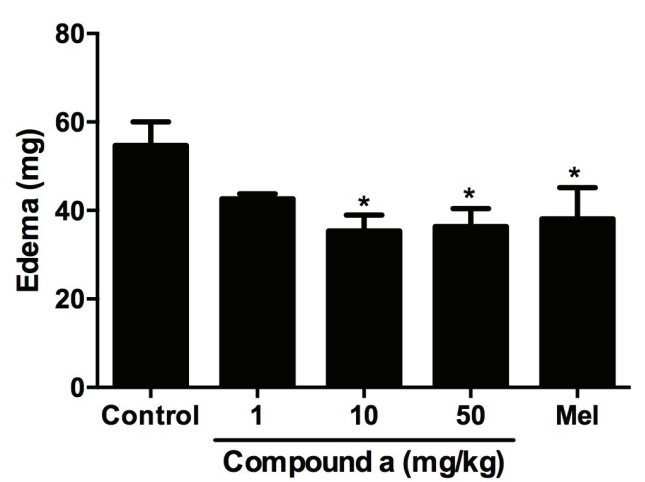

Figure 3 - Effects of compound a on formalin-induced nociception. Inhibition of the formalin-induced licking (s) response (a) in the first and (b) second phases, and (c) edema $(\mathrm{mg})$. Data are reported as mean \pm S.E.M of 7 to 8 animals per group. Statistical analysis was performed by One-way ANOVA followed by Newman-Keuls' test. $\left(^{*}\right)$ denotes $\mathrm{P}<$ $0.05,(* *)$ denotes $\mathrm{P}<0.01$ and $(* * *)$ denotes $\mathrm{P}<0.001$ when compared to the control group. 
by $64 \%(\mathrm{p}<0.001), 85 \%(\mathrm{p}<0.001)$ and $93 \%$ $(\mathrm{p}<0.0001)$, respectively, when compared to the control group (Figure 3b). Meloxicam (50 mg/ $\mathrm{kg})$ decreased the licking time by $67 \%(\mathrm{p}<0.01)$ (Figure 3b).

Compound a markedly reduced the formalininduced paw edema formation (ANOVA: F $(4,33)$ $=2.999, \mathrm{p}<0.05)$ by $35 \%(10 \mathrm{mg} / \mathrm{kg} ; \mathrm{p}<0.05)$ and $33 \%(50 \mathrm{mg} / \mathrm{kg} ; \mathrm{p}<0.05)$, when compared to the control group (Figure 3c). Compound a at a dose of $1 \mathrm{mg} / \mathrm{kg}$ did not have any effect in reducing paw edema formation induced by formalin $(\mathrm{p}>0.05)$ (Figure 3c). Meloxicam (50 mg/kg) reduced the formalin-induced paw edema formation by $30 \%$ (p $<0.05$ ) (Figure 3c).

\section{DISCUSSION}

The present study demonstrated, for the first time, that a new class of quinoline derivatives containing (compound $\mathbf{c}$ and $\mathbf{d}$ ) or not selenium (compound a) presented in vitro antioxidant activity in brain and liver, respectively. In addition, thiol peroxidaselike activity, DPPH and ABTS radical-scavenging activities are not involved in the possible antioxidant mechanism of these compounds. Compounds did not present a thiol-group oxidant effect, as demonstrated by thiol oxidase-like and $\delta$-ALA-D activities. In vivo experiments showed that compound a presented antinociceptive and antiedematogenic effects in the formalin test.

A close inspection of the results revealed that the antioxidant activity of quinoline derivatives containing (compound $\mathbf{c}$ and $\mathbf{d}$ ) or not selenium (compound a) against lipid peroxidation induced by SNP depended on the chemical structure and analyzed tissue. Compound a, a quinoline derivative without selenium, exhibited the highest antioxidant activity in the TBARS assay, since it was the only quinoline derivative that completely restored the TBARS content to control levels. Moreover, compound a had a higher $\mathrm{I}_{\max }$, indicating the higher effectiveness of this compound when compared to the other compounds (b-d). Compound a has the nitrogen atom in the aromatic ring and it forms a radical which contributes to its antioxidant action.

Since compound a has antioxidant effect, substitutions at specific points in the quinoline system were made with the aim of increasing this activity. Regarding the chemical structure of compounds b-d, all of them presented the phenylselanyl group and different substituents, $\mathrm{H}$ (b), $\mathrm{Cl}$ (c) and $\mathrm{NO}_{2}$ (d), bounded to the aromatic ring of the quinoline system. In the liver, the results demonstrated that compounds $\mathbf{c}$ and $\mathbf{d}$, with $\mathrm{Cl}$ and $\mathrm{NO}_{2}$ as substituent, respectively, had a better antioxidant effect in the TBARS assay than compound $\mathbf{b}$, but this effect was inferior to that of compound $\mathbf{a}$. In the brain, only compound $\mathbf{d}$ partially reduced the lipid peroxidation. Evidence has shown that the introduction of selenium atom may improve the biological activity of compounds (Arteel and Sies 2001, Rossato et al. 2002). However, in the present study, we demonstrated that the insertion of a phenylselanyl group worsened the antioxidant effect of compound a in the liver, but improved it in the brain, demonstrating that antioxidant action depended on the analyzed tissue.

Moreover, compounds $\mathbf{c}$ and $\mathbf{d}$ are quinoline derivatives with an electron withdrawing group $(\mathrm{Cl}$ and $\mathrm{NO}_{2}$, respectively) into the aryl group of the quinoline system, while compound $\mathbf{b}$ is a quinoline derivative with a neutral group $(\mathrm{H})$ in the aryl group of the quinoline system. These results suggest that the introduction of an electron withdrawing into the aromatic ring of quinoline system influences the antioxidant effect of quinoline derivatives. In addition, the data from the literature have evidenced that the introduction of electron withdrawing groups into the organochalcogen compounds has an important role in establishing their application as antioxidants (Prigol et al. 2009, Luchese et al. 2012). 
Radicals DPPH and ABTS have been used to determine the scavenger mechanism of antioxidant compounds (Govindappa et al. 2011, Hamsar et al. 2011, Silva et al. 2015). Our results demonstrated that compounds a-d did not present DPPH and ABTS radical-scavenger activities, suggesting that radical-scavenger activity is not the mechanism by which compounds displayed an antioxidant effect. In fact, other studies showed that organoselenium compounds or quinoline derivatives with important antioxidant properties did not present DPPH and ABTS radical-scavenger activities (Luchese and Nogueira 2010, Luchese et al. 2012, Savegnago et al. 2013).

The antioxidant action of compounds a-d could be explained by their ability to mimic the activity of thiol peroxidase. In this study, we demonstrated that compounds a-d did not demonstrate thiol peroxidase-like activity. The findings of this study clearly indicated that the antioxidant effect of compounds a-d is not related to the thiol oxidase-like activity. Moreover, it is difficult to clearly explain why these compounds did not show enzyme-like activity. Accordingly, other studies have revealed that some organochalcogen compounds with antioxidant activity did not exhibit thiol peroxidase-like activity (Souza et al. 2009, Gay et al. 2010).

Even though compounds have an antioxidant effect, it is important to study the toxicity of these compounds. The quinoline derivatives containing or not selenium did not present thiol oxidase-like activity and did not inhibit $\delta$-ALA-D activity in vitro, demonstrating a poor potential toxicity of these compounds. In fact, thiol-groups oxidation is an estimation of the cytotoxicity of molecules (Prigol et al. 2012). Some studies have described that the toxicity of organoselenium compounds could be associated with $\delta$-ALA-D activity inhibition. $\delta$-ALA-D is a sulfhydryl-containing enzyme, which can be inhibited, in different prooxidant situations; this enzyme can be used as a marker of toxicity (Bechara 1996, Pinton et al. 2010, Rocha et al. 2012). This is a satisfactory result since most organochalcogen compounds showed activity to oxidize thiol groups (Nogueira et al. 2004, Luchese et al. 2007, Gay et al. 2010).

In vitro antioxidant assays prompted the choice of compound a for the evaluation of antinociceptive, anti-inflammatory and antiedematogenic activities in the formalin test. In the TBARS assays, compound a had higher $\mathrm{I}_{\max }$. This parameter indicates the effectiveness of compounds. Thus, compound a had higher effectiveness than other compounds in the TBARS assays. Moreover, compound a exhibited the highest antioxidant activity in the TBARS assay, since it was the only quinoline derivative that completely restored the TBARS content to control levels.

The results of this study showed that compound a, a quinoline derivative without selenium, reduced the nociceptive behavior in the first (nociceptive) and second (inflammatory) phases and it presented an antiedematogenic effect in reducing the paw edema formation in the formalin test. These results reinforce the antinociceptive, anti-inflammatory and antiedematogenic potential of compound $\mathbf{a}$. The formalin test has long been used as a screening tool for the assessment of antinociceptive property of new agents and it is considered a reliable model of tonic pain of the inflammatory type (Pavin et al. 2011, Lima et al. 2013, Sari et al. 2014). The formaldehyde induces damage in tissues to imitate acute post lesion pain in humans with a biphasic response (Bonjardim et al. 2011). In the acute phase, called neurogenic, nociception is caused by direct activation of the nociceptive fibers, which release substance $\mathrm{P}$, glutamate, and bradykinin, among other pain mediators (Luccarini et al. 2006). The late phase, which is inflammatory, is mediated by the release of inflammatory mediators, such as nitric oxide, excitatory amino acids (aspartate and glutamate), prostacyclins, prostaglandins (PGE2), and leukotrienes, which will later stimulate the 
spinal cord and cause pain (Bonjardim et al. 2011, Venancio et al. 2011). In accordance, literature data have indicated that quinoline derivative compounds (present important) important antinociceptive activity (Nogueira et al. 2003, Pavin et al. 2011, Sari et al. 2014, Pinz et al. 2016).

In conclusion, the results of this investigation demonstrated the in vitro antioxidant effect of quinoline derivatives containing or not selenium against lipid peroxidation. However, antioxidant mechanisms of compounds were not found, ruling out thiol peroxidase-like activity, and DPPH and ABTS radical-scavenger activities. Moreover, we demonstrated the antinociceptive, anti-inflammatory and antiedematogenic effects of compound a, the best antioxidant compound. Further studies are necessary to demonstrate other pharmacological properties of these compounds in vivo, as well as the mechanisms involved in the antioxidant and antinociceptive effects.

\section{ACKNOWLEDGMENTS}

Financial support by Universidade Federal de Pelotas, Universidade Federal de Santa Maria, Coordenação de Aperfeiçoamento de Pessoal de Nível Superior (CAPES), Conselho Nacional de Desenvolvimento Científico e Tecnológico $(\mathrm{CNPq})$ and Fundação de Amparo à Pesquisa do Estado do Rio Grande do Sul (FAPERGS)/CNPq (PRONEX) research grant \# 10/0005-1 is gratefully acknowledged. C.L. and G.Z. are recipients of CNPq fellowship.

\section{REFERENCES}

ABDEL-WAHAB BAAND SALAMA RH. 2011. Venlafaxine protects against stress-induced oxidative DNA damage in hippocampus during antidepressant testing in mice. Pharmacol Biochem Behav 100: 59-65.

ARTEEL GE AND SIES H. 2001. The biochemistry of selenium and the glutathione system. Environ Toxicol Pharmacol 10: 153-158.
BECHARA EJ. 1996. Oxidative stress in acute intermittent porphyria and lead poisoning may be triggered by 5-aminolevulinic acid. Braz J Med Biol Res 29: 841-851.

BRADFORD MM. 1976. A rapid and sensitive method for the quantification of microgram quantities of protein utilizing the principle of protein-dye binding. Anal Biochem 72: 248-254.

BONJARDIM LR ET AL. 2011. Sida cordifolia leaf extract reduces the orofacial nociceptive response in mice. Phytother Res 25: 1236-1241.

CHOI CW. 2002. Antioxidant activity and free radical scavenging capacity between Korean medicinal plants and flavonoids by assay - guided comparasion. Plant Science 163: 1161-1168.

ELMANN GL. 1959. Tissue sulfhydryl groups. Arch Biochem Biophys 82: 70-77.

GAY BM, LUCHESE C, NOGUEIRA CW, WENDLER P, MACEDO A AND DOS SANTOS AA. 2010. Antioxidant effect of functionalized alkyl-organotellurides: a study in vitro. J Enzyme Inhib Med Chem 25: 467-475.

GOVINDAPPA M, BHARATH N, SHRUTHI H AND SANTOYO G. 2011. In vitro Antioxidant Activity and Phytochemical Screening of Endophytic Extracts of Crotalaria pallida. Free Rad Antiox 1: 79-86.

GUPTA RK, PATEL AK, SHAH N, CHAUDHARY AK, JHA UK, YADAV UC, GUPTA PK AND PAKUWAL U. 2014. Oxidative stress and antioxidants in disease and cancer: a review. Asian Pac J Cancer Prev 15: 4405-4409.

HAMSAR MN, ISMAIL S, MORDI MN, RAMANATHAN S AND MANSOR SM. 2011. Antioxidant activity and the effect of different parts of areca catechu extracts on Glutathione-S-Transferase activity in vitro. Free Rad Antiox 1: 28-33.

HUNSKAAR S AND HOLE K. 1987. The formalin test in mice: dissociation between inflammatory and noninflammatory pain. Pain 30: 103-114.

IBRAHIM M, HASSAN W, MEINERZ DF, SANTOS M, KLIMACZEWSKI CV, DEOBALD AM, COSTA MS, NOGUEIRA CW, BARBOSA NBV AND ROCHA JBT. 2012. Antioxidant properties of diorganoyl diselenides and ditellurides: modulation by organic aryl or naphthyl moiety. Mol Cell Biochem 371: 97-104.

KOUZNETSOV VV, MENDEZ LYV AND GOMEZ CMM. 2005. Recent progress in the synthesis of quinolines. Curr Org Chem 9: 141-161.

KUBERA M, OBUCHOWICZ E, GOEHLER L, BRZESZCZ J AND MAES M. 2011. In animal models, psychosocial stress-induced (neuro)inflammation, apoptosis and reduced neurogenesis are associated to the onset of depression. Prog Neuropsychopharmacol Biol Psychiatry 35: 744-759.

LIMA AC ET AL. 2013. Orofacial antinociceptive effect and antioxidant properties of the hydroethanol extract of 
Hyptis fruticosa salmz ex Benth. J Ethnopharmacol 146: 192-197.

LUCCARINI P, CHILDERIC A, GAYDIER AM, VOISIN D AND DALLEL R. 2006. The orofacial formalin test in the mouse: a behavioral model for studying physiology and modulation of trigeminal nociception. J Pain 7: 908-914.

LUCHESE C, BRANDÃO R, ACKER CI AND NOGUEIRA CW. 2012. 2,2'-Dipyridyl diselenide is a better antioxidant than other disubstituted diaryl diselenies. Mol Cell Biochem 367: 153-163.

LUCHESE C AND NOGUEIRA CW. 2010. Diphenyl diselenide in its selenol form has dehydroascorbate reductase and glutathione S-transferase-like activity dependent on the glutathione content. J Pharm Pharmacol 62: 1146-1151.

LUCHESE C, ZENI G, ROCHA JBT, NOGUEIRA CW AND SANTOS FW. 2007. Cadmium inhibits $\delta$-aminolevulinate dehydratase from rat lung in vitro: interaction with chelating and antioxidant agents. Chem Biol Interact 165: 127-137.

MAES M, GALECKI P, CHANG YS AND BERK M. 2011. A review on the oxidative and nitrosative stress (O\&NS) pathways in major depression and their possible contribution to the (neuro)degenerative processes in that illness. Prog Neuropsychopharmacol Biol Psychiatry 29: 676-692.

MANJUNATHA JR, BETTADAIAH BK, NEGI PS and SRINIVAS P. 2013. Synthesis of quinoline derivates of tetrahydrocurcumin and zingerone and evaluation of their antioxidant and antibacterial attributes. Food Chem 136(2): 650-658.

MUGESH G AND SINGH H. 2000. Synthetic organoselenium compounds as antioxidants: glutathione peroxidase activity. Chem Soc Rev 29: 347-357.

NOGUEIRA CW, QUINHONES EB, JUNG EA, ZENI G AND ROCHA JBT. 2003. Anti-inflammatory and antinociceptive activity of diphenyl diselenide. Inflamm Res 52: 56-63.

NOGUEIRA CW AND ROCHA JBT. 2010. Diphenyl diselenide a Janus-faced molecule. J Braz Chem Soc 21: 2055-2071.

NOGUEIRA CW, ZENI G AND ROCHA JBT. 2004. Organoselenium and organotellurium compounds: toxicology and pharmacology. Chem Rev 104: 6255-6285.

OHKAWA H, OHISHI N AND YAGI K. 1979. Assay for lipid peroxides in animal tissues by thiobarbituric acid reaction. Anal Biochem 95: 351- 358.

PAVIN NF, DONATO F, CIBIN FWS, JESSE CR, SCHNEIDER PH, SALLES HD, SOARES A, ALVES D AND SAVEGNAGO L. 2011. Antinociceptive and antihypernociceptive effects of Se-phenyl thiazolidine-4carboselenoate in mice. Eur J Pharmacol 668: 196-176.
PINTON S, LUCHESE C AND NOGUEIRA CW. 2010. Comparison of the antioxidant properties and the toxicity of $p, p$-dichlorodiphenyl ditelluride with the parent compound, diphenyl ditelluride. Biol Trace Elem Res 139: 206-216.

PINZ M, REIS AS, DUARTE V, DA ROCHA MJ, GOLDANI BS, ALVES D, SAVEGNAGO L, LUCHESE C AND WILHELM EA. 2016. 4-Phenylselenyl-7-chloroquinoline, a new quinolone derivative containing selenium, has potential antinociceptive and anti-inflammatory actions. Eur J Pharmacol 780: 122-128.

PRIGOL M, BRUNING CA, ZENI G AND NOGUEIRA CW. 2009. Protective effect of disubstituted diaryl diselenides on cerebral oxidative damage caused by sodium nitroprusside. Biochem Eng J 45: 94-99.

PRIGOL M, NOGUEIRA CW, ZENI G, BRONZE MR AND CONSTANTINO L. 2012. In vitro metabolism of diphenyl diselenide in rat liver fractions: Conjugation with GSH and binding to thiol groups. Chem Biol Interact 200: 65-72.

RAJENDRAN P, NANDAKUMAR N, RENGARAJAN T, PALANISWAMI R, GNANADHAS EM, LAKSHMINARASAIAH U, GOPAS J AND NISHIGAKI I. 2014. Antioxidants and human diseases. Clin Chim Acta 436: 332-347.

RE R, PELLEGRINI N, PROTEGGENTE A, PANNALA A, YANG M AND RICEEVANS C. 1999. Antioxidant activity applying an improved ABTS radical cátion decolorization assay. Free Rad Biol Med 26: 1231-1237.

RIEDEL R, MARRASSINI C, ANESINI C AND GORZALCZANY S. 2015. Anti-inflammatory and antinociceptive activity of Urera aurantiaca. Phytother Res 29: 59-66.

ROCHA JBT, SARAIVA RA, GARCIA SC, GRAVINA FS AND NOGUEIRA CW. 2012. Aminolevulinate dehydratase ( $\boldsymbol{\delta}$-ALA-D) as marker protein of intoxication with metals and other pro-oxidant situations. Toxicol Res 1: $85-102$

ROSSATO JI, KETZER LA, CENTURIÃO FB, SILVA SJ, LÜDTKE DS, ZENI G, BRAGA AL, RUBIN MA AND ROCHA JB. 2002. Antioxidant properties of new chalcogenides against lipid peroxidation in rat brain. Neurochem Res 27: 297-303.

SANCINETO L, PICCIONI M, DE MARCO S, PAGIOTTI R, NASCIMENTO V, BRAGA AL, SANTI C AND PIETRELLA D. 2016. Diphenyl diselenide derivatives inhibit microbial biofilm formation involved in wound infection. BMC Microbiol 16: 220-230.

SARAIVA MT, KRÜGER R, BALDINOTTI RSM, LENARDÃO EJ, LUCHESE C, SAVEGNAGO L, WILHELM EAAND ALVES D. 2016. 7-Chloroquinoline1,2,3-triazoyl Carboxylates: Organocatalytic Synthesis and Antioxidant Properties. J Braz Chem Soc 1: 41-53. 
SARI MH, SOUZA AC, ROSA SG, SOUZA D, RODRIGUES OR AND NOGUEIRA CW. 2014. Contribution of dopaminergic and adenosinergic systems in the antinociceptive effect of p-chloro-selenosteroid. Eur J Pharmacol 725: 79-86.

SASSA S. 1982. Delta-aminolevulinic acid dehydratase assay. Enzyme 28: 133-145.

SAVEGNAGO L, JESSE CR, SANTOS AS, ROCHA JBT AND NOGUEIRA CW. 2008. Mechanisms involved in the antinociceptive effect caused by diphenyl diselenide in the formalin test. J Pharm Pharmacol 60: 1679-1686.

SAVEGNAGO L, VIEIRA AI, SEUS N, GOLDANI BS, CASTRO MR, LENARDÃO EJ AND ALVES D. 2013. Synthesis and antioxidant properties of novel quinolinechalcogenium compounds. Tetrah Lett 54: 40-44.

SENG HLAND TIEKINK ERT. 2012. Anti-cancer potential of selenium- and telluriumcontaining species: opportunities abound. Appl Organomet Chem 26: 655-662.

SHEEBA MS AND ASHA VV. 2009. Cardiospermum halicacabum ethanol extract inhibits LPS induced COX-2, TNF-alpha and iNOS expression, which is mediated by NFkappa B regulation, in RAW264.7 cells. J Ethnopharmacol 124: 39-44.

SILVA GL ET AL. 2015. Antioxidant, analgesic and antiinflammatory effects of lavender essential oil. An Acad Bras Cienc 87: 1397-1408.
SOUZA ACG, LUCHESE C, NETO JS AND NOGUEIRA CW. 2009. Antioxidant effect of a novel class of telluroacetilene compounds: Studies in vitro and in vivo. Life Sci 84: 351-357.

STEIN AL, ROSÁRIO AR AND ZENI G. 2015. Synthesis of 3-organoseleno-substituted quinolines through cyclization of 2-aminophenylprop-1-yn-3-ols promoted by Iron(III) chloride with diorganyl diselenides. Eur J Org Chem 2015: 5640-5648

THAIPONGA K, BOONPRAKOBA U, CROSBYB K, CISNEROS-ZEVALLOSC L AND BYRNEC DH. 2006. Comparison of ABTS, DPPH, FRAP, and ORAC assays for estimating antioxidant activity from guava fruit extracts. J Food Compos Anal 19: 669-675.

VENANCIO AM, ONOFRE ASC, LIRA AF, ALVES PB, BLANK AF, ANTONIOLLI AR, MARCHIORO M, ESTEVAM CS AND ARAUJO BS. 2011. Chemical composition, acute toxicity, and antinociceptive activity of the essential oil of a plant breeding cultivar of Basil (Ocimum basilicum L.). Planta Med 77: 825-829.

WILHELM EA, MACHADO NC, PEDROSO AB, GOLDANI BS, SEUS N, MOURA S, SAVEGNAGO L, JACOB RG AND ALVES D. 2014. Organocatalytic synthesis and evaluation of 7-chloroquinoline-1,2,3triazoyl carboxamides as potential antinociceptive, antiinflammatory and anticonvulsant agent. RSC Advances 4: 41437-41445. 